\title{
Temporal changes in the distribution of attention in the visual field in response to precues
}

\author{
TIMOTHY D. MURPHY and CHARLES W. ERIKSEN \\ University of Illinois, Urbana-Champaign, Champaign, Illinois
}

\begin{abstract}
This experiment measured the changes in the distribution of attentional processing in the visual field in response to precues. The hypothesis of an analogue movement of the attentional "spotlight" across the visual field was also tested. Choice reaction time to stimuli was determined in a response competition paradigm. Subjects viewed a central fixation point and the stimuli (the letters $A$ and $U$ ) were presented at retinal eccentricities of $1^{\circ}, 2^{\circ}$, and $3^{\circ}$ along the horizontal meridian to the left and right of fixation. Two letters were simultaneously presented in all experimental conditions. For compatible noise, the second letter was identical to the target, and for incompatible noise, the second letter was the other letter of the target set. The target letter in a trial was designated by an underline that either occurred simultaneously with the onset of the two-letter display or preceded the display by $25,50,75,100$, or 175 msec. The target letter occurred equally often in each of the six display positions and the noise letter equally often in each of the remaining positions. The response competition effect of an incompatible noise letter was found to be a joint function of target and noise-letter location, an effect that changed over time from onset of the underline precue to the onset of the display. With simultaneous onset, interference was largely independent of target and noise location, but with increasing asynchrony of onset, noise interference became increasingly confined to locations adjacent to the target. No evidence was found for an analogue movement of an attentional "spotlight" across the visual field.
\end{abstract}

Numerous experiments have shown that the time required to identify a stimulus in a visual display is appreciably shortened if the position in the visual field to be occupied by the stimulus is precued. With choice-reactiontime tasks that use letter stimuli, the reduction in reaction time (RT) can be on the order of $100 \mathrm{msec}$ with displays of 12 letters or more (Colegate, Hoffman, \& C. W. Eriksen, 1973; C. W. Eriksen \& Hoffman, 1972), but with single-letter displays the reduction is on the order of 30 to $40 \mathrm{msec}$ (C. W. Eriksen \& Hoffman, 1973, 1974; Hoffman, 1975). Similar precuing effects are obtained for simple RT on detection tasks (Posner, Nissen, \& Ogden, 1978; Posner, Snyder, \& Davidson, 1980). With choice RT, the stimulus onset asynchrony (SOA) between the onset of the precue and the onset of the target achieves its maximum effect in the region of 150 to $250 \mathrm{msec}$. That is, the RT-SOA function approaches asymptote in this region.

These results readily lend themselves to conceptions of visual attention as a resource or capacity that can be concentrated at locations in the visual field independently of foveal fixation (C. W. Eriksen \& St. James, 1986; C. W. Eriksen \& Yeh, 1985; Jonides, 1980, 1983; Posner et al., 1980; Shaw, 1978). The precue facilitates performance

\footnotetext{
This research was supported by Public Health Service Research Career Program Award K6-MH-22014 to the second author and by United States Public Health Service Research Grant MH-012006, also to the second author. Requests for reprints should be sent to Charles W. Eriksen, Department of Psychology, University of Illinois, Urbana-Champaign, 603 E. Daniel, Champaign, IL 61820.
}

by providing a head start to resource concentration at the designated area. When the target appears, processing is expedited either because attentional resources are already concentrated at the location or because there is a shorter latency for the concentration to occur. In the case of simple discriminations-such as those involved in detection tasks, where concentrated attention might not be necessary-the concentration can still improve performance by expediting the processing of the signal.

Jonides (1983) suggested that these attentional resources can operate in two modes. In the distributed mode, resources are evenly distributed throughout the display area and all of the stimuli are parallel processed. In the concentrated mode, stimuli are processed serially. C. W. Eriksen and Yeh (1985) confirmed Jonides's findings but proposed that the two modes were poles on a continuum of attentional distribution. They suggested a zoom-lens analogy in which the field of attention can vary in size. All stimuli within the field are parallel processed, but the efficiency of the processing varies inversely with the size of the field. Attentional distribution is also considered to be dynamic. If the task or discrimination is easy, a response criterion can be satisfied with few resources or with a wide attentional field. If the resources are unable to process sufficiently to satisfy the response or decision criterion, attention starts to zoom in on a selected target. Resources continue to concentrate on an individual stimulus until enough information is obtained to make a decision.

There is evidence that the size or area of attentional concentration can vary. LaBerge (1983) found that attention 
could be precued to a single letter or increased to include a five-letter word. Furthermore, Egeth (1977) reported that discrimination latency increased as the size of the attended area increased, and Beck and Ambler (1973) found a similar effect for discrimination accuracy. However, other investigators have failed to find the inverse relation between the size of the attended area and discrimination accuracy (Lappin \& Uttal, 1976; Shiffrin, McKay, \& Shaffer, 1976). More recently, C. W. Eriksen and St. James (1986) showed that different-sized subareas of a display could be precued, with discrimination latency varying inversely with the number of display positions precued. They also found a gradient of processing efficiency around the cued location that extended about $1.5^{\circ}$ from the border of the cued area. A similar gradient had previously been suggested in an experiment conducted by C. W. Eriksen and Hoffman (1973).

The C. W. Eriksen and St. James (1986) data indicated that a change in the locus of attentional concentration in the visual field occurs discretely. In the absence of a precue, attention was distributed evenly over the entire display area. As the SOA between the occurrence of the precue and the occurrence of the target increased, processing efficiency for stimuli in the immediate area of the cued location increased, with a corresponding decrease in the processing of stimuli more remotely located from the target position.

This account of how attention changes locus is at variance with the conclusions of Tsal (1983a) and of Shulman, Remington, and McLean (1979). These investigators employed a spotlight metaphor of visual attention. Tsal concluded that the attentional spotlight traverses the visual field in an analogue manner at a rate of approximately $8 \mathrm{msec}$ per degree of angle. Shulman et al. conclued not only that the attentional shift was an analogue movement at constant velocity, but furthermore, that the attentional spotlight processed all stimuli in its path as it moved from one locus to another. However, C. W. Eriksen and Murphy (1987) pointed out certain methodological problems in these experiments, as well as a lack of internal consistency of the data, that make these conclusions suspect.

We had two main objectives for the present experiment. First, we wished to measure the change in processing efficiency, as reflected in RT, for different display locations as the temporal interval between a precue and display presentation increased. In essence, we attempted to portray the dynamic change in attentional concentration over time as attention was directed to the precued location. Second, we wished to determine whether the rate at which attentional resources are concentrated on a precued location varies with the retinal eccentricity of the location from the fixation point in the display, and if so, whether a stimulus intervening between the fixation point and the cued location shows evidence of enhanced processing.

\section{DESIGN AND RATIONALE}

The experimental task was designed to determine the choice RT to the capital letters A and U. Subjects first viewed a central fixation cross, and then letter stimuli were presented at retinal eccentricities of $1^{\circ}, 2^{\circ}$, or $3^{\circ}$ of visual angle to the left and to the right of the fixation cross along the horizontal meridian. Two letters were presented simultaneously in all experimental conditions. In the compatible noise condition, the second letter was identical to the target letter, and in the incompatible noise condition, the second letter was the other letter of the target set. The target letter in a trial was designated by an underline, which could either occur simultaneously with the presentation of the two-letter display ( $\mathrm{SOA}=0 \mathrm{msec}$ ) or precede the display by SOA values of $25,50,75,100$, or $175 \mathrm{msec}$. The target letter occurred equally often in each of the six positions of eccentricity and the noise letter occurred equally often in each of the remaining five positions.

From the results of previous experiments we expected that $R T$ to the target would decrease with increasing values of SOA, with the RT-SOA function becoming asymptotic by 175-msec SOA (C. W. Eriksen \& Hoffman, 1974; C. W. Eriksen \& St. James, 1986; Tsal, 1983a). Furthermore, we expected target RT to increase with increasing eccentricity of the target location (C. W. Eriksen \& Schultz, 1978; Lefton \& Haber, 1974; Tsal, 1983a). To the extent that they are processed, incompatible noise letters were expected to lead to response competition and significantly increase RT to the target letter (Coles, Gratton, Bashore, C. W. Eriksen, \& Donchin, 1985; B. A. Eriksen \& C. W. Eriksen, 1974; Flowers \& Wilcox, 1982; Grice, Canham, \& Schafer, 1982). Compatible noise letters, on the other hand, were expected to have appreciably less effect on target RT.

The experimental strategy was to measure the responsecompetitive effect of the incompatible noise letter on target RT as a joint function of target and noise letter location as SOA varied from 0 to $175 \mathrm{msec}$. On the basis of previous findings, we anticipated that attention would tend to be uniformly distributed over the display at 0-msec SOA (C. W. Eriksen \& Yeh, 1985; C. W. Eriksen \& St. James, 1986; Jonides, 1983). Thus both target and noise would be processed essentially simultaneously, and the location of the noise with respect to the target would make little difference. However, increasing the time interval between the precue and the target would give attentional resources time to begin to develop at the cued location. Concomitantly, the effect of noise should become increasingly position dependent. Noise at the more remote locations with reference to the target should first begin to lose its effectiveness, and by the time the RT-SOA function approaches asymptote, the interfering effect of incompatible noise should be confined mainly to positions adjacent to the target. 
The possible movement of an "attentional spotlight" across the visual field to the cued target location can be assessed in terms of interactions between the RT-SOA functions for the different target eccentricities. Differences in RT should be greatest among the three eccentricities at 0 -msec SOA. This is based upon the assumption made by Tsal (1983a) and by Shulman et al. (1979) that at 0 msec SOA the attentional spotlight is on the fixation point. Consequently, when the target is presented, the spotlight must traverse the distance to the target. Thus at $0-\mathrm{msec}$ SOA, RT to the targets at the three locations will differ due both to their retinal eccentricity and to the differential travel time required for the spotlight to reach these locations. But when the RT-SOA function becomes asymptotic (SOA $=175 \mathrm{msec})$, the spotlight will have already traversed the field to the target location before the target is presented. The differences in RTs among the three locations should then reflect only differences in processing efficiency as a function of retinal eccentricity. Also, the differential effectiveness of incompatible noise letters in the path as opposed to out of the path of the hypothetical spotlight sweep can be determined.

\section{METHOD}

\section{Subjects}

Eight university students ( 2 men and 6 women) with normal or corrected-to-normal vision served as paid volunteers.

\section{Apparatus and Materials}

Stimuli were displayed with a three-field Model GA Scientific Prototype tachistoscope that had been modified by replacing the standard bulbs with Sylvania F4T5/CWX fluorescent lamps. The luminance of each tachistoscopic field was set at $8 \mathrm{~mL}$, as measured with a Spectra Spot Photometer.

Field 1 contained a black fixation dot which measured $1.5 \mathrm{~mm}$ and subtended $0.08^{\circ}$ of visual angle (VA). The dot was mounted on a clear vinyl card placed in front of a white background card, which provided the necessary contrast. Field 1 was illuminated at all times except when either Field 2 or Field 3 was illuminated.

Field 2 contained the precue display along with the fixation dot. The precue was a black underline marker which measured $11 \times 3 \mathrm{~mm}$ and subtended $.55 \times .15^{\circ} \mathrm{VA}$. The precue was mounted on a clear vinyl card and was placed in front of a white background card. One of six precue displays was presented to the subject on each trial. The underlines were at a distance of $1^{\circ}, 2^{\circ}$, or $3^{\circ} \mathrm{VA}$ to the left or right of the fixation dot. The precue was separated from the target letter that it underlined by a distance of $4 \mathrm{~mm}$, or $.2^{\circ} \mathrm{VA}$.

Field 3 contained the target- and noise-letter display mounted on a clear vinyl card in front of a white background card. The letter display was illulminated immediately after the termination of the precue display and remained illuminated for a total of $25 \mathrm{msec}$ on every trial. The target letter was either a capital A or a capital U, and measured $7.2 \times 5.5 \mathrm{~mm}$ and subtended $0.35^{\circ} \mathrm{VA}$. The letters were Zip-A-Tone 24-point Demi-Bold No. 39-24 CLN. The target letter on a given trial was at a distance of $1^{\circ}, 2^{\circ}$, or $3^{\circ}$ to the left or right of fixation on the horizontal meridian. The target letter was always underlined by the same underline cue that was presented in Field 2. Also mounted on the clear vinyl card was a single noise letter, which was also either a capital A or U of the same size as the target letter. The noise letter on a given trial was never underlined and could occupy any of the five locations not occupied by the target letter.
The subject initiated a trial by pressing a microswitch to trigger the tachistoscope and PDP-11 computer, which both displayed and recorded the $\mathrm{RT}$ in milliseconds. The subject responded by using his/her preferred hand to push a spring-loaded switch left or right, depending on whether the target letter was $A$ or $U$.

\section{Procedure}

Prior to initiating a trial, the subject was instructed to be sure the fixation dot was in good focus and to respond as quickly as possible while trying to maintain perfect accuracy. Following each trial, the subject was told both the speed and the accuracy of his/her response.

When a subject initiated a trial, the fixation field went off and was replaced by the precue display for $0,25,50,75,100$, or $175 \mathrm{msec}$. Following termination of the precue, the target- and noise-letter display was illuminated for $25 \mathrm{msec}$ and then replaced by the fixation field.

Subjects completed 2-h sessions on each of 6 consecutive days, with the first day entirely devoted to practice. Each session consisted of six blocks of 33 trials, with each block being run under one of the six SOA intervals. The order of blocks that were run under each SOA was counterbalanced both within and across subjects. Each block contained 33 trials presented in a random order plus a repetition of error trials, which were presented in a continuous manner at the end of the block.

The 33 trials within a block contained 3 no-noise control trials in which the target was presented at one of the three distances from fixation. The other 30 trials consisted of pairings of a single target and a single noise letter. Fifteen different target-noise position combinations were possible: the target could occur at any of three distances from fixation and the noise letter could occur in any of the five positions not occupied by the target. Within a given block, 10 targets occurred at each of the three distances. Half of the targets were As and half were Us, and half of the targets occurred to the left of fixation and half to the right. The 15 different position combinations were combined with two different noise-compatibility conditions to produce the 30 different trial types. The noise letter on a given trial could be compatible (the same as the target) or incompatible (the opposite response target letter). Thus the 30 different trial types within each block contained every possible target-noise location configuration for both compatible and incompatible trial types.

Each of the 8 subjects provided means for the 33 trial types at each of six SOAs. The means provided by each subject were based on five observations.

\section{RESULTS AND DISCUSSION}

The error data revealed an overall error rate of $8 \%$. The correlation between the number of errors and the mean correct RT for the 36 stimulus types at each of the six SOAs was $r(214)=.573(p<.001)$. The significant positive correlation militates against the possibility of a speed/accuracy tradeoff's obscuring the interpretation of mean differences in RT.

The main analysis of the data was a repeated measures analysis of variance (ANOVA) performed on the mean RT values of individual subjects obtained under the different conditions of the experiment. To simplify the analysis and its interpretation, we used as a factor whether the noise and target letters were on the same side of fixation, rather than the actual distance of the noise letter from the target letter. Thus the analysis was a $6 \times 2 \times 3 \times 2 \times 8$ (SOA $\times$ same- vs. opposite-side noise $\times$ target distance $\times$ noise compatibility $\times$ subjects) design. All main ef- 
fects were significant. These effects were SOA $[F(5,35)$ $=14.14, p<.001]$, noise side $[F(1,7)=16.02$, $p<.005]$, target distance from fixation $[F(2,14)=$ $31.96, p<.001]$, and noise compatibility $[F(1,70)=$ $40.73, p<.001]$. The significant two-way interactions were SOA $\times$ noise side $[F(5,35)=2.85, p<.03]$, SOA $\times$ compatibility $[F(5,35)=2.69, p<.03]$, noise side $\times$ compatibility $[F(1,7)=14.38, p<.01]$, and target distance $\times$ compatibility $[F(2,14)=16.05, p<.001]$. There was also a significant three-way interaction between SOA, noise side, and target distance $[F(10,70)=1.96$, $p<.05]$.

The significant main effects for SOA, noise compatibility, and target distance from fixation were expected on the basis of prior research, which we reviewed above. Not only were the effects significant, but the directions of the differences were consistent with these prior findings. Thus RT to the target decreased consistently from 459 to $414 \mathrm{msec}$ as the SOA from the occurrence of the precue to the occurrence of the target increased from 0 to $175 \mathrm{msec}$. Incompatible noise produced more interference in RT to the target than did compatible noise ( 447 vs. $408 \mathrm{msec}$ ), and RT increased as the target location moved from $1^{\circ}$ from fixation to $3^{\circ}\left(1^{\circ}, 408 \mathrm{msec} ; 2^{\circ}\right.$, $\left.428 \mathrm{msec} ; 3^{\circ}, 447 \mathrm{msec}\right)$. The noise-side effect resulted from longer RTs to the target when the noise letter was on the same side of fixation as the target.

Figure 1 shows the RT-SOA functions for targets located at each of the three retinal eccentricities. The decreasing RTs as the precue preceded the target by increasingly longer intervals are consistent with results obtained in our previous experiments (Colegate et al., 1973; C. W. Eriksen \& Hoffman, 1973; C. W. Eriksen \& St. James, 1986) and those obtained by others (e.g., Tsal, 1983a). The functions are somewhat shallower than those obtained with more complex displays, which is in keeping with previous findings that the facilitation obtained by precuing is dependent upon display complexity (Colegate et al., 1973). The separated functions for targets at $1^{\circ}, 2^{\circ}$, and $3^{\circ}$ eccentricity reflect the increase in RT as the target location is moved toward the peripheral retina. However, the shapes of the three functions are highly similar. Increases in retinal eccentricity appear to elevate the functions by a constant amount, a conclusion supported by the lack of a significant or suggestive interaction between retinal eccentricity and SOA $[F(10,70)<1]$.

Eye movements were not monitored in this experiment, but the functions in Figure 1 show that changes in eye fixation could not have contributed to the facilitation obtained by precuing. In previous work we have found that saccadic eye movements in response to precues have a mean latency in excess of $200 \mathrm{msec}$ (Colegate et al., 1973). The data in Figure 1 show that the majority of the facilitation in RT was obtained by an SOA of $25 \mathrm{msec}-$ much too rapid for even the fastest saccade. Furthermore, if eye movements were contributing to the decrease in RT, we would expect the RT-SOA functions to show increasing facilitation as SOAs approached $200 \mathrm{msec}$. Therefore, we included an increasing number of trials in which saccades had occurred.

We have previously attributed the facilitation in RT obtained by precuing to the early concentration of processing resources at the cued location (C. W. Eriksen \& St. James, 1986; C. W. Eriksen \& Yeh, 1985). In the present experiment we have a second measure of the change in the distribution of processing resources in response to the precue. If processing resources are concentrated around the cued location; the disrupting effect of an incompatible noise letter in the visual field should be inversely related to its distance from the precued location. Noise close to the target should share in the more rapid processing arising from resource concentration (C. W. Eriksen \& Hoffman, 1973; C. W. Eriksen \& St. James, 1986). This enhanced processing of incompatible noise should increase response-competitive effects, with a consequent slowing of target RT. In Figure 2, the mean RT to targets is shown as a function of whether the noise was located on the same side of fixation as the tar-

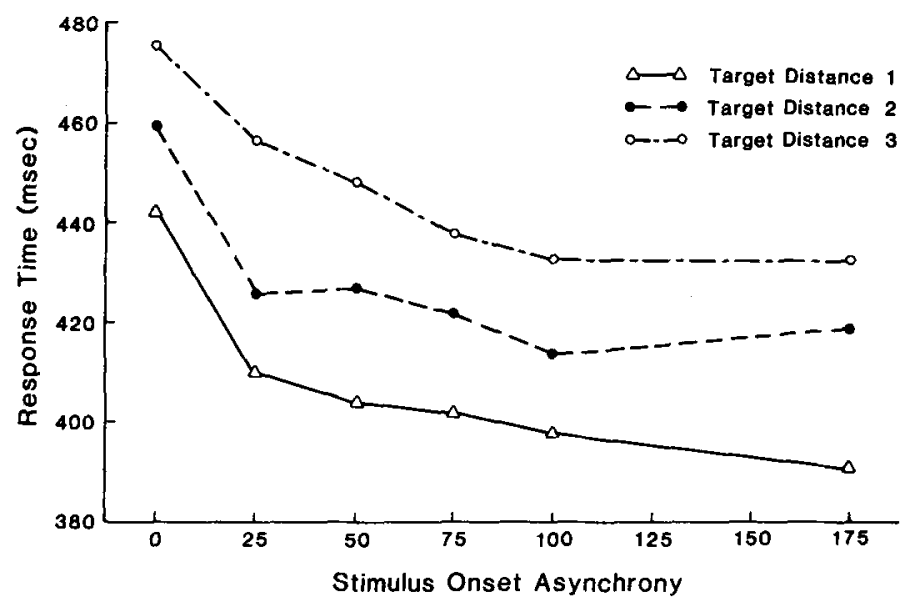

Figure 1. Mean response times to targets located at $1^{\circ}, 2^{\circ}$, and $3^{\circ}$ eccentricity as a function of the $\mathrm{SOA}$ between the underlined precue and the target. 


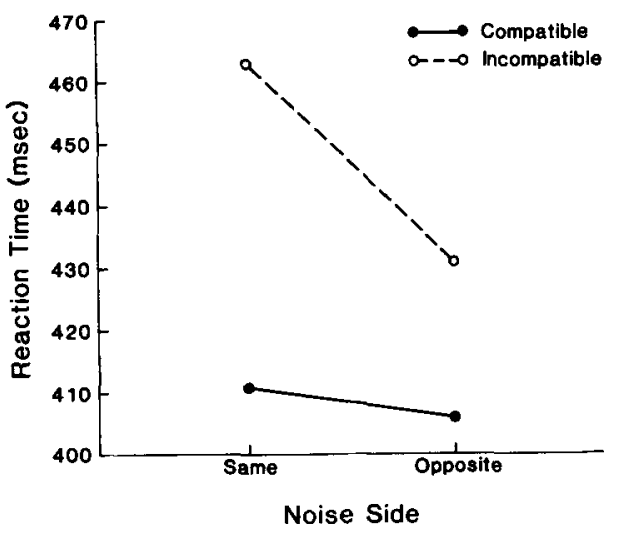

Figure 2. Mean response times to targets as a function of whether or not the noise letter was on the same side of fixation as the target letter. Separate functions are shown for when the noise was responsecompatible and when it was response-incompatible.

get or on the opposite side. The figure shows the results separately for response-compatible and responseincompatible noise.

Not only did response-incompatible noise show a greater interference with target RT, but the interference was appreciably greater if the noise letter was located on the same side of fixation as the target. With responsecompatible noise, on the other hand, interference was less overall and there was little difference attributable to the location of the compatible noise. This result for compatible noise is consistent with previous results, referenced above, showing that response-compatible noise has few interfering effects. Therefore, the location of compatible noise relative to the target is a matter of indifference.

The above analysis shows a proximity effect of the incompatible noise letter relative to its distance from the target. Interference is greater if the noise letter occurs on the same side of fixation as the target, which on the aver- age would make it closer to the target. We can make a finer grained analysis of target-noise distance by examining the effect of the incompatible noise letter on target RT when target and noise letter are separated by $1^{\circ}, 2^{\circ}$, $3^{\circ}, 4^{\circ}, 5^{\circ}$, or $6^{\circ}$ of visual angle. Because target eccentricity is a potent determiner of target RT, it is necessary to look at target-noise distance effects with target eccentricity held constant. This we can do by looking at the noise distance effect separately for each of the three target eccentricities. Also, since we would expect the noise distance effects to change over time in response to the precue, it is desirable to look at these effects at 0 - and 175-msec SOA.

Figure 3 shows target RT at 0 - and $175-\mathrm{msec}$ SOAs for each of the three target eccentricities (data for target location to the left and right of fixation have been combined) when the incompatible noise letter was located at one of the other five possible locations. Thus, for example, the center panel in the figure represents those trials on which the target was at $1^{\circ}$ eccentricity (left or right of fixation) and the noise letter occurred at $2^{\circ}$ or $3^{\circ}$ eccentricity on the same side of fixation as the target or at $1^{\circ}, 2^{\circ}$, or $3^{\circ}$ on the opposite side of fixation. The left panel provides corresponding data for the target at $2^{\circ}$ eccentricity and the right panel for the target at $3^{\circ}$ eccentricity. This manner of presentation facilitates the comparison of the interfering effects of the incompatible noise letter in each of the five possible locations at the 0 - and $175-\mathrm{msec}$ SOA conditions. The difference in the height of the bars for the two SOA conditions illustrates the relative change in interference.

Figure 3 shows three salient characteristics that we have previously noted. RT increases for both 0 - and 175 -msec SOAs, irrespective of the noise location, as target location moves outward from $1^{\circ}$ to $3^{\circ}$. This increase reflects the significant effect obtained for target location. The significant effect of SOA is shown in the shorter RT for the

Incompatible Noise

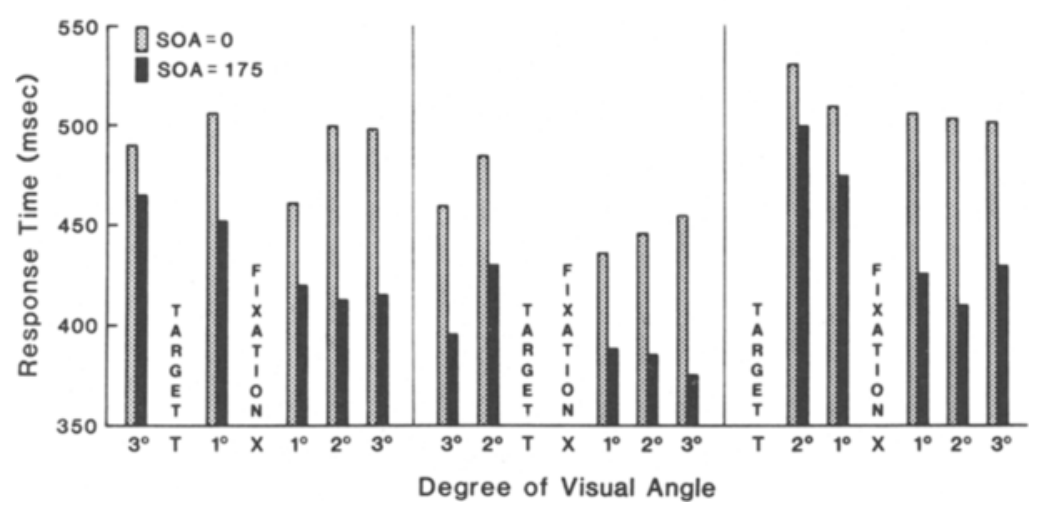

Figure 3. Mean response times to the target letter at 0 - and 175-msec SOAs as a joint function of target and incompatible noise letter location. The center panel shows data for the target at $1^{\circ}$ eccentricity (to the right or left of fixation) and the incompatible noise letter in one of the remaining five locations. The panel to the left shows comparable data for the target at $2^{\circ}$ eccentricity and the panel to the right is for the target at $3^{\circ}$ eccentricity. 
175-msec SOA, again irrespective of noise and target location. However, we found the most interesting characteristic of the data to be the change in the effectiveness of noise location as the SOA between cue and target is increased to $175 \mathrm{msec}$. At $\mathrm{O}-\mathrm{msec} \mathrm{SOA}$, when the cue and target are presented simultaneously, the interference of an incompatible noise letter appears to be much less dependent upon its position in the display than at $175-\mathrm{msec}$ SOA. By $175-\mathrm{msec}$ SOA, interference is markedly reduced if the noise letter occurs on the side of fixation opposite that of the target. In general, interference varies inversely with distance from the target. The latter characteristic of the data is more pronounced as target location is moved farther from fixation. Humphreys's (1981) data suggest that the interference effects of adjacent incompatible stimuli lessen as the target moves closer to fixation. The present data are consistent with this finding.

This interpretation is supported by statistical tests. Six two-way ANOVAs (noise location $X$ subjects) were performed for the 0 - and 175-msec conditions for each of the three target locations. For 0-msec SOA, none of the main effects for noise location were significant ( $p>.05$ ), but for 175-msec SOA, all were. Although these analyses indicate that at 0 -msec SOA the differences in effectiveness of noise at the different locations were within random variation, there is still a suggestion in the data that even when targets occur without a precue, a noise letter immediately adjacent to the target causes more interference than one in the opposite visual field. This suggests that in some proportion of the trials, even at 0-msec SOA, attention is concentrated to some degree at the general target locus before the target is sufficiently identified for the response. This partial concentration is sufficient to enhance processing of nearby noise letters.

In general, the data are consistent with an interpretation that in the absence of a precue, attention is rather uniformly distributed over the display area. Precuing target location serves to concentrate attention in and around the cued location. For whatever reasons, concentration of attention on the cued location is not precise. Stimuli within $1^{\circ}$ of the target are also favored in processing. But when contrasted with no precue, the processing of the target has been appreciably facilitated and stimuli falling beyond $1^{\circ}$ of angle from the target location have not shared in this facilitation.

The development of this change in attentional distribution over time can be seen in Figure 4. The figure presents the same breakdown of the data as does Figure 3, but here 0 -msec and 25-msec SOAs are contrasted. The RT-SOA functions in Figure 1 show that appreciable attentional focusing has occurred in an SOA as short as $25 \mathrm{msec}$. We would expect, therefore, that there would have been a corresponding change in the effectiveness of incompatible noise relative to its location with respect to the target. At 25-msec SOA there is evidence of a change in the distribution or concentration of attention. Within this $25 \mathrm{msec}$, the greatest interference has shifted to the same side of the display as the target, and there is a clear tendency for the greatest interference to occur at the locations immediately adjoining the target.

From previous research we know that compatible noise letters in the display produce relatively little interference in RT to the target, compared with incompatible noise. However, even when response competition does not appear to be involved, irrelevant visual signals occurring along with the target in choice-RT tasks have been found to increase RT (C. W. Eriksen, Hamlin, \& Daye, 1973; C. W. Eriksen \& Schultz, 1978; Grice et al., 1982; Treisman, Kahneman, \& Burkell, 1983). The main ANOVA summarized above showed the expected significant difference between compatible and incompatible noise and further revealed that noise compatibility interacted with SOA,

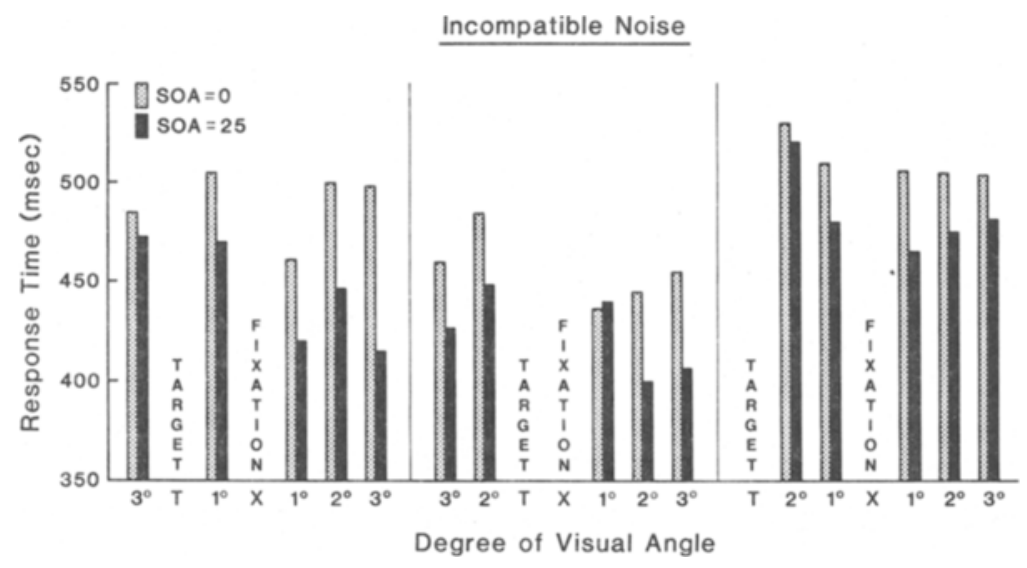

Figure 4. Mean response times to the target letter at 0-msec and 25-msec SOAs as a joint function of target and incompatible noise letter location. The center panel shows data for the target at $1^{\circ}$ eccentricity (to the right or left of fixation) and the incompatible noise letter in one of the remaining five locations. The panel to the left shows comparable data for the target at $2^{\circ}$ eccentricity and the panel to the right shows data for the target at $3^{\circ}$ eccentricity. 


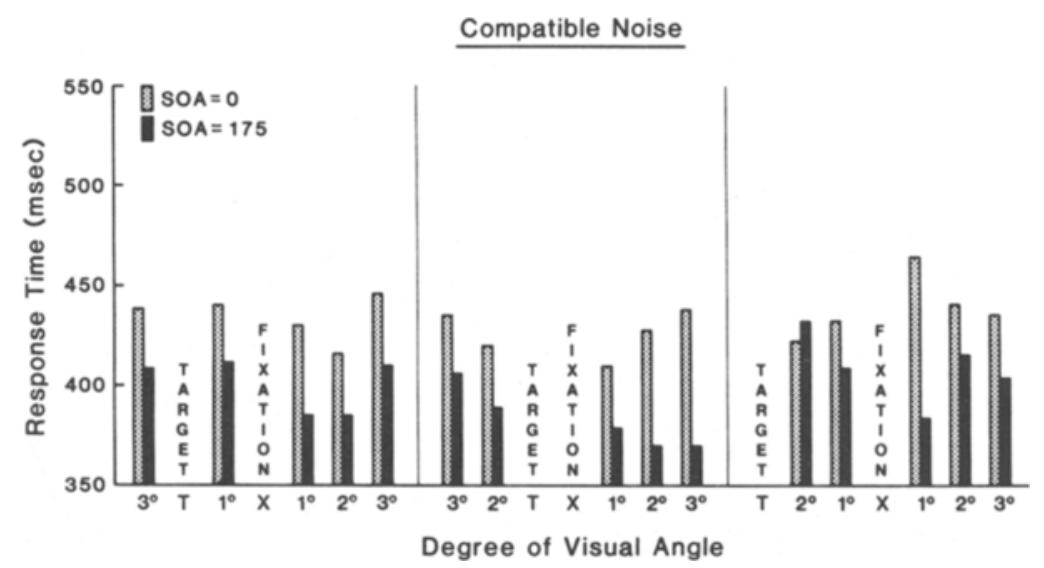

Figure 5. Mean response times to the target letter at 0-msec and 175-msec SOAs as a joint function of target and compatible noise letter location. The center panel shows data for the target at $1^{\circ}$ eccentricity (to the right or left of fixation) and the incompatible noise letter in one of the remaining five locations. The panel to the left shows comparable data for the target at $2^{\circ}$ eccentricity and the panel to the right shows data for the target at $3^{\circ}$ eccentricity.

target distance from fixation, and whether the noise was on the same or opposite side of the display as the target. These interactions are to be expected if compatible noise causes little interference, relative to incompatible noise. In the extreme case, in which compatible noise has no interference effect, the location of a compatible noise letter in the display should be a matter of indifference. Interference as a function of noise location should not vary with SOA or target location.

Figure 5 shows the RTs for the trials in which the target letter was presented with a compatible noise letter. The three panels represent the three eccentricities of the target, and RTs for both 0 - and 175-msec SOAs are shown for when the noise letter occupied each of the remaining display positions. Comparison of these data with those in Figure 3 shows that at all target locations and at both SOAs, RTs to the target were faster when the noise letter was response compatible. $\mathrm{RT}$ is, in all cases but one, faster at 175 -msec SOA, a finding that reflects the faster process- ing of the target when its location is precued by $175 \mathrm{msec}$. The most important finding is that noise location relative to the target has little effect, not only at 0-msec SOA but, most important, at 175 -msec SOA. This is most apparent when compared with the position-dependent effect of incompatible noise at 175-msec SOA seen in Figure 3, suggesting that the non-response-competitive effect found in extraneous stimuli (C. W. Eriksen et al., 1973; Treisman et al., 1983) when they are presented in the visual field along with choice-RT targets is essentially nonspecific and is not dependent upon or excluded by concentrated or focalized attention.

In the above discussion we assumed that compatible noise does exert some interference effect, albeit slight. (This assumption has gotten a little ahead of our statistical tests.) In Figure 6, mean target RT is shown for compatible noise as a function of both SOA and performance under no-noise control condition. The data in Figure 6 were analyzed in a three-way ANOVA (SOA, conditions,

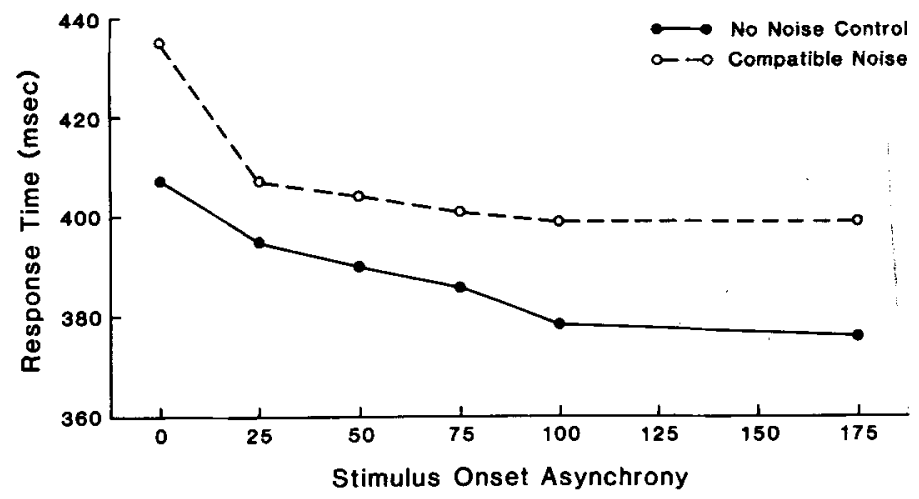

Figure 6. Mean response time to targets as a function of $\mathrm{SOA}$ for the compatible and the no-noise control conditions. 
and subjects). The difference between conditions was significant $(p<.01)$, but the interaction was not $(p>.20)$. The data are quite clear in showing that compatible noise increases target RT over a no-noise condition. The function for the compatible noise lies above that for the no-noise condition at all values of SOA. ${ }^{1}$

The position-dependent incompatible noise effects shown in Figure 3 are confounded with retinal eccentricity. As reported earlier, target RT increased by approximately $20 \mathrm{msec}$ for each degree of eccentricity. If we infer that it takes $20 \mathrm{msec}$ longer to process a letter at $2^{\circ}$ eccentricity than at $1^{\circ}$, then as target and noise positions vary there will be combinations of the two locations in which the target is processed faster than the noise. There will also be combinations in which the noise is located in positions that cause the noise to be processed faster than the target. For example, if the target location is at $2^{\circ}$ and the incompatible noise occurs at $1^{\circ}$, the noise should be more effective than if the noise occurred at $3^{\circ}$. The effect would be similar to that of presenting target and noise at different temporal asynchronies, a procedure that has previously been found to differentially determine the amount of response competition the noise exerts on response to the target (C. W. Eriksen \& Schultz, 1979). This possible confounding will not affect the interpretation that the noise interference effects shift to the target side of the visual field, but interpretation of small differences in the effectiveness of noise bordering the target must be tempered by these considerations. Fortunately, such effects are expected to be quite small. Prior research (C. W. Eriksen \& Schultz, 1979) has shown that temporal asynchronies in the range of $40 \mathrm{msec}$ between the presentation of the noise letter and the presentation of the target yield results comparable to those of simultaneous presentation.

Although the data in Figure 3 show a clear shift of processing efficiency in the visual field in response to precues, the means by which this shift is carried out must still be determined. Spotlight models of visual attention have stimulated research concluding that the attentional spotlight moves across the visual field in an analogue fashion at a rate of so many milliseconds per degree of visual angle (Shulman et al., 1979; Tsal, 1983a). On the other hand, Remington and Pierce (1984) concluded that attentional movement is discrete, or that, if it is analogue, the rate is proportional to the distance to be traveled. Furthermore, Tsal and Shulman et al. disagree about whether irrelevant stimuli in the path of the attentional spotlight are processed during the sweep. Tsal concluded that attentional processing ceases during the sweep until the new target is reached, whereas Shulman et al. interpreted their data as showing that attention processes all stimuli in the path of the spotlight as it moves to its new target. In addition to the disagreement among these three experiments, all suffer from methodological problems and the lack of internal consistency of their data (C. W. Eriksen \& Murphy, 1987).

The present experiment provides negative evidence for the proposition that attention moves like a spotlight across the visual field. If we assume, as have Shulman et al. (1979), Tsal (1983a), and Remington and Pierce (1984), that the attentional spotlight is located on the fixation point at the beginning of a trial, then a constant velocity movement should require more time to move to $3^{\circ}$ eccentricity than to $1^{\circ}$ eccentricity. However, RT to targets at these two locations should also differ due to processing time differences at these retinal eccentricities. The variable SOA between the precue and the target presentation allows us to separate the effects of these two variables.

When the target and the location cue occur simultaneously, differences in RT among the three target locations will reflect processing time differences for these retinal eccentricities plus the time it takes to initiate and move the attentional spotlight to the respective locations. But when the SOA between the precue and the target presentation is long enough to allow the attentional spotlight to reach the precued location before the target appears, then RT differences for targets at $1^{\circ}, 2^{\circ}$, or $3^{\circ}$ will reflect only processing time differences for these three eccentricities. In terms of the RT-SOA functions for targets at $1^{\circ}, 2^{\circ}$, and $3^{\circ}$, a constant-velocity analogue movement of the attentional spotlight would predict larger differences among these three functions at a $0-$ msec SOA than at the SOA values at which the functions have become asymptotic. In other words, an interaction is predicted.

We have seen, however, that there was no suggestion of an interaction between retinal eccentricity and SOA (see Figure 1). The constant RT differences among these three retinal eccentricities across the SOA range lead us to the conclusion that attention is deployed as rapidly to a target at $3^{\circ}$ eccentricity as to a target at $1^{\circ}$ eccentricity.

The failure to obtain a significant interaction between target distance and SOA is inconsistent with any constantvelocity analogue movement of attention. Further evidence is at variance with the specific characteristics of this analogue movement as it was proposed by Shulman et al. (1979). If, as they proposed, attention processes all stimuli falling in the path of the sweep as it moves from central fixation to target location, then a noise letter falling in the path would have a greater interfering effect on target RT than would a letter equally close to the target location but lying outside the path. If we examine the condition in the present experiment in which the target was presented at $2^{\circ}$ eccentricity, we can compare the effectiveness of an incompatible noise letter at $1^{\circ}$ and at $3^{\circ}$ eccentricity on the same side of fixation as the target. For both locations, the noise is immediately adjacent to the target, but must traverse the $1^{\circ}$ location, but not the $3^{\circ}$ location, in order to reach the hypothetical attention sweep to the target. Examination of the data in Figure 3 for the $2^{\circ}$ target location shows that at $175-\mathrm{msec}$ SOA there is actually slightly more interference from the $3^{\circ}$ noise than from the $1^{\circ}$ noise. Interference is determined by proximity to the target, rather than by whether the noise lies between fixation and the target location.

This conclusion is reinforced by the data from the $3^{\circ}$ target location. With this target location, an incompatible noise letter at either $1^{\circ}$ or $2^{\circ}$ on the same side as the 
target would have to be traversed by the attentional spotlight. At 175-msec SOA, by which time we can presume that the sweep has been completed, the interference for these two noise locations should be equal. But, as the data in Figure 3 show, the interference for the $2^{\circ}$ noise is appreciably greater. The extent to which a noise letter is processed depends on its distance from the cued target location and not on whether it lies between the fixation point and the cued location.

\section{GENERAL DISCUSSION}

Although we have reservations, which we will discuss later, a model of attention as resources or capacities that can be concentrated or distributed in the visual field provides a good organization and description of the present data. C. W. Eriksen and his associates (C. W. Eriksen \& St. James, 1986; C. W. Eriksen \& Yeh, 1985) have proposed a zoom-lens model that embodies these properties. A zoom lens at a low power setting has a wide field of view but little magnification or resolution of detail. The field of view constricts as the power is increased, but there is a corresponding increase in the amount of detail available from the objects that remain in the field of view. In keeping with the analogy, attentional resources can be distributed over the visual field, but processing is relatively slow in the distributed mode and there is a limit to the amount of information that can be extracted from the individual stimuli in the field. If the information about a stimulus is insufficient to make a decision while in the distributed mode, attentional resources begin to concentrate or zoom in on the stimulus. Concentration continues until the accumulation of information is sufficient to satisfy a criterion for decision.

Stimuli within the attentional field are processed in parallel. If the field is large, a number of stimuli are processed simultaneously but at a gross level that is incapable of fine discriminations. When attentional resources are highly concentrated, only a single stimulus, or a part thereof, is processed, but with optimal detail resolution. This change in the attentional field is also reflected in the speed with which discriminatory detail becomes available.

The concentration of resources occurs over time. The facilitation in RT that occurs with spatial location precuing is attributed to the head start provided by precuing on concentration of resources at this location, so that when the target arrives it is met by a high concentration. Processing is expedited by the elimination of any delay while resources are concentrated and then by the faster processing this concentration provides.

The zoom-lens model applied to the data of the present experiment provides the following account. At 0 -msec SOA, resources are spread over the six possible display positions. The cue, the target, and the noise letter appear simultaneously. The discrimination is a relatively easy one and attentional concentration is not usually required. But due to the distribution of resources over all six display positions, the target and the noise are parallel processed, and the location of the noise letter with reference to the target is a matter of indifference. When the cue precedes the target and the noise, attentional concentration begins to occur at the cued location. Not only does this concentration facilitate the processing of the target when it arrives, but the concomitant reduction of resources at other display positions results in a slowing of the processing of noise letters occupying these positions.

In addition to the present data, other evidence indicates that in the absence of a precue, or at 0-msec SOA between precue and target, attention is distributed over the entire display with parallel processing of all the stimuli (C. W. Eriksen \& St. James, 1986; C. W. Eriksen \& Yeh, 1985; Jonides, 1983). Furthermore, there are findings that the concentration of attention is not sharply demarcated at the cued position. Instead, it shows a gradient extending about $1.5^{\circ}$ around the cued area (C. W. Eriksen \& Hoffman, 1974; C. W. Eriksen \& St. James, 1986). This processing gradient is also apparent in the present data. As shown in Figure 3, the effectiveness of a noise letter declined as its distance from the target increased and the SOA lengthened. But even at 175-msec SOA, when the RT-SOA functions appear to have asymptoted, a noise letter $1^{\circ}$ away from the target still exerted an appreciable interference effect relative to locations two or more degrees away. There was evidence in the $\mathrm{C}$. W. Eriksen and St. James experiments that, in addition to the increase in attentional resources over time at a spatial location, there was a corresponding sharpening of the focus. However, several experiments suggest that there is a limit to how fine the attentional focus can be drawn (B. A. Eriksen \& C. W. Erikson, 1974; C. W. Eriksen \& Hoffman, 1973; C. W. Eriksen \& St. James, 1986; Hoffman, 1975). At least for areas in the visual field not too far removed from the fovea, the attentional focus appears to consist of an area of about $3^{\circ}$ in which stimulus processing is enhanced.

How the attentional focus is shifted from one area of the visual field to another is still an open question. The present data do not support analogue movement of the focus across the visual field, whether or not such hypothesized movement involves the processing of stimuli encountered along the path (Shulman et al., 1979). The RT-SOA functions in Figure 3 show no temporal effects that can be attributed to the time required to move attention to the three different retinal eccentricities. The only effect apparent in these three functions is accounted for by the differential processing efficiency of these different retinal locations. As we pointed out above, the present data suggest that at 0 -msec SOA, attentional resources are distributed evenly over the entire display area. The kind of attentional shift suggested by the present data is not consistent with a moving spotlight. Rather, the occurrence of the precue initiates the beginning of a build-up of resources at the cued area, and the rate of this build-up is independent of the distance from foveal fixation, at least within the range of eccentricities studied. 
The changing effectiveness of location of incompatible noise letters as SOA increases from $0 \mathrm{msec}$ to $175 \mathrm{msec}$ poses serious problems for late-selection models of attention, such as those of Hoffman (1979) and Duncan (1980). These models can accommodate the well-documented finding that precuing a target location in a multistimulus display facilitates target processing. Target RT is reduced due to the early presentation of selection criteria. These models become strained, however, when only single-letter displays are used and the target location is precued (C. W. Eriksen \& Hoffman, 1973, 1974; Hoffman, 1975), or when the task is detection and the location of the target is precued (Posner et al., 1978; Posner et al., 1980). Since only a single letter or signal occurs in the visual field, it is difficult to see how selection criteria are needed. However, Duncan (1981) proposed that, in the absence of a precued location, all locations in the display are indexed and the facilitation that occurs with the precue is attributable to the elimination of the time required to index these empty locations (but see Tsal, 1983b).

In the present experiment, if we attribute the SOA effect to the early presentation of selection information, we must account for the interference effect of incompatible noise letters. We could posit that there is spatial inaccuracy in the selection process. On some proportion of the trials a letter in a noncued location is selected and processed to the level of incipient response activation before the selection is corrected. With longer intervals between the presentation of the precue and the display, spatial selection accuracy improves. Thus in the present experiment, when 175-msec SOA is reached, selection errors occur only for positions $1^{\circ}$ of angle from the cued location. However, the error of spatial selection at $0-\mathrm{msec}$ SOA is about as apt to occur for a position $5^{\circ}$ removed from the actual cued location as it is for a position $1^{\circ}$ away. Furthermore, there is substantial evidence that the interference effect produced by incompatible noise stimuli is due to the parallel or simultaneous processing of the noise letter along with the target (Coles et al., 1985).

It seems that the most parsimonious interpretation is that the precue leads to facilitation of stimuli occurring in the cued location and that, furthermore, the demarcation of the facilitated area is not precise, but shows a gradient of decreasing facilitation along its borders. This interpretation can be reconciled with late-selection models such as that of Hoffman (1979) and the very similar model of Duncan (1980) by attributing the facilitative effects to mechanisms or processes other than attention. One possibility is that the precue provides the visual system with a head start in localizing stimuli in the visual field. There is considerable evidence that location and features of stimuli are processed at least partially independently (B. A. Eriksen \& C. W. Eriksen, 1974; Estes, Allmeyer, \& Reder, 1976; Treisman \& Gelade, 1980). Most recently, Coles et al. (1985) found that feature processing precedes location processing. If features, or even identity of form stimuli, were available before their specific and relative locations were established in the visual field, we would have a means by which incompatible noise stimuli could prime competing responses. A correct response requires location information. If the features or even the identities of the letters in the display were available to the subject, a correct response would still require location information to determine which letter was in the target position.

If precuing acts by initiating location processing, the facilitation obtained for target RT would arise because the precue had given an early start to location processing. Thus, when the features or identities of the stimuli were available, response to the target would not have to wait for location determination. The results of the 0-msec SOA condition in the present experiment would be described as the result of parallel processing of all stimuli in the display, as is assumed in the Hoffman (1979) model for Stage 1 . Thus, the interference produced by an incompatible noise letter would be relatively independent of its position or distance from the target. As SOA lengthened, location processing activated by the precue would shorten the time required to fix the location of a stimulus as its features and identity became available. If location processing were also facilitated for positions immediately adjacent to the precue, we would expect that noise letters located next to the target position would share in the more rapid integration of their features at a location in the visual field. Thus, at 175-mse SOA in the present experiment, the obtained facilitation of RT for stimuli falling at the cued location and $1^{\circ}$ away would be the expected outcome.

Attributing the facilitation of a precue to a reduction in the time needed to complete location processing by the visual system is certainly a more prosaic interpretation than conceptualizations envisaging the concentration of attentional resources at different loci in the visual field. However, we feel that there is enough evidence for the separate processing of features and location to make the idea worth pursuing. If it should prove true, it would enable late-selection theories to again assume a dominant position as explanations of attentional phenomena.

\section{REFERENCES}

BECK, J., \& AMBLER, B. (1973). The effects of concentrated and distributed attention on peripheral acuity. Perception \& Psychophysics, 14, 217-224.

Colegate, R., Hoffman, J. E., \& Eriksen, C. W. (1973). Selective encoding from multielement visual displays. Perception \& Psychophysics, 14, 217-224.

Coles, M. G. H., Gratton, G., Bashore, T. R., Eriksen, C. W., \& DonCHIN, E. (1985). A psychophysical investigation of the continous flow model of human information processing. Joumal of Experimental Psychology: Human Perception \& Performance, 11, 529-553.

Duncan, J. (1980). The locus of interference in the perception of simultaneous stimuli. Psychological Review, 87, 272-300.

Duncan, J. (1981). Directing attention in the visual field. Perception \& Psychophysics, 30, 90-93.

EGETH, H., (1977). Attention and preattention. In G. H. Bower (Ed.). The psychology of learning and motivation (Vol. 11, pp. 277-320). New York: Academic Press. 
ERIKSEN, B. A., ERIKSEN, C. W. (1974). Effects of noise letters upon the identification of a target letter in a nonsearch task. Perception \& Psychophysics, 16, 143-149.

Eriksen, C. W., Hamlin, R. M., \& Daye, C. (1973). Aging adults and rate of memory scan. Bulletin of the Psychonomic Society, 1, 259-260.

Eriksen, C. W., Hoffman, J. E. (1972). Some characteristics of selective attention in visual perception determined by vocal reaction time. Perception \& Psychophysics, 11, 169-171.

Eriksen, C. W., \& Hoffman, J. E. (1973). The extent of processing of noise elements during selective encoding from visual displays. Perception \& Psychophysics, 14, 155-160.

ERIKSEN, C. W., \& Hoffman, J. E. (1974). Selective attention: Noise suppression or signal enhancement? Bulletin of the Psychonomic Society, 4, 587-589.

ERIKSEN, C. W., MURPHY, T. (1987). Movement of the attentional focus across the visual field: A critical look at the evidence. Perception \& Psychophysics, 42, 299-305.

ERIKSEN, C. W., \& SCHULTZ, D. W. (1978). Temporal factors in visual information processing. In J. Requin (Ed.), Attention and performance VII (p. 1-26). New York: Academic Press.

ERIKSEN, C. W., \& Schultz, D. W. (1979). Information processing in visual search: A continuous flow conception and experimental results. Perception \& Psychophysics, 25, 249-263.

ERIKSEN, C. W., \& ST. JAMES, J. D. (1986). Visual attention within and around the field of focal attention: A zoom lens model. Perception \& Psychophysics, 40, 225-240.

ERIKSEN, C. W., \& YEH, Y. (1985). Allocation of attention in the visual field. Journal of Experimental Psychology: Human Perception \& Performance, 11, 583-597.

Estes, W. K., Allmeyer, D. H., Reder, S. M. (1976). Serial position functions for letter identification at brief and extended exposure durations. Perception \& Psychophysics, 19, 1-15.

FLowErs, J. H., \& WiLCox, N. (1982). The effect of flanking context on visual classification: The joint contributions of interactions at different processing levels. Perception \& Psychophysics, 32, 581-591.

Grice, G. R., Canham, L., \& Schafer, C. (1982). Development of associative and perceptual interference. Perception \& Psychophysics, 32, 375-387.

Hoffman, J. E. (1975). Hierarchical stages in the processing of visual information. Perception \& Psychophysics, 18, 348-354.

Hofrman, J. E. (1979). A two-stage model of visual search. Perception \& Psychophysics, 25, 319-327.

HUMPHREYS, G. W. (1981). On varying the span of visual attention: Evidence for two modes of spatial attentions. Quarterly Journal of Experimental Psychology, 33A(Part 1), 17-30.

JONIDES, J. (1980). Toward a model of the mind's eye. Canadian Joumal of Psychology, 34, 103-112.

JONIDES, J. (1983). Further toward a model of the mind's eye's movement. Bulletin of the Psychonomic Society, 21, 247-250.
LABERGE, D. (1983). Spatial extent of attention to letters in words. Journal of Experimental Psychology: Human Perception \& Performance, 9, 371-379.

LAPPIN, J. S., \& UTTAL, W. R. (1976). Does prior knowledge facilitate the detection of visual targets in random noise? Perception \& Psychophysics, 20, 367-374.

LeFTON, L. A., \& HABER, R. N. (1974). Information extraction from different retinal locations. Journal of Experimental Psychology, 102, 975-980.

Posner, M. I., Nissen, M. J., \& OGden, W. C. (1978). Attended and unattended processing modes: The role of set for spatial location. In N. H. L. Pick \& I. J. Saltzman (Eds.), Modes of perceiving and processing information (pp. 137-157). Hillsdale, NJ: Erlbaum.

Posner, M. I., SNyder, R. R., \& Davidson, D. J. (1980). Attention and the detection of signals. Joumal of Experimental Psychology: General, 109, 160-174.

Remington, R., \& Pierce, L. (1984). Moving attention: Evidence for time-invariant shifts of visual selective attention. Perception \& Psychophysics, 35, 393-399.

SHAw, M. L. (1978). A capacity allocation model for reaction time. Journal of Experimental Psychology: Human Perception \& Performance, 4, 586-598.

Shiffrin, R. M., McKay, D. P., \& Shaffer, W. D. (1976). Attending to forty-nine spatial positions at once. Journal of Experimental Psychology: Human Perception \& Performance, 2, 14-22.

Shulman, G. L., Remington, R. W., \& McLean, J. P. (1979). Moving attention through visual space. Journal of Experimental Psychology: Human Perception \& Performance, 5, 522-526.

Treisman, A., \& Gelade, G. (1980). A feature-integration theory of attention. Cognitive Psychology, 12, 97-136.

Treisman, A., Kahneman, D., \& Burkell, J. (1983). Perceptual objects and the cost of filtering. Perception \& Psychophysics, 33, 527-532.

Tsal, Y. (1983a). Movements of attention across the visual field. Joumal of Experimental Psychology: Human Perception \& Performance, 9 , 523-530.

TsaL, Y. (1983b). On interpreting the effects of location preknowledge: A critique of Duncan. Perception \& Psychophysics, 34, 297-298.

\section{NOTE}

1. Because some noise location effects may occur relative to the target, the data for the compatible condition in Figure 6 and in the ANOVA are based only on those trials in which the compatible noise occurred in one of the three retinal eccentricities on the side of fixation opposite the target location.

(Manuscript received March 5, 1987; revision accepted for publication July $8,1987$. ) 